\title{
Tests on Anchorage of Naturally Corroded Reinforcement in Concrete
}

Lundgren, K., Tahershamsi, M., Zandi, K, and Plos, M.

Materials and Structures, 2014,

DOI 10.1617/s11527-014-0290-y

The original publication is available at the publisher's web site http://link.springer.com/article/10.1617/s11527-014-0290-y

The article is accepted for publication and is copyrighted by RILEM.

Readers must contact RILEM for permissions to reprint or use the material in any form. 


\title{
Tests on Anchorage of Naturally Corroded Reinforcement in Concrete
}

\author{
K. Lundgren ${ }^{1}$, M. Tahershamsi ${ }^{1}$, K. Zandi ${ }^{2}$, M. Plos ${ }^{1}$ \\ ${ }^{1}$ Chalmers University of Technology, Gothenburg, Sweden \\ ${ }^{2}$ CBI Swedish Cement and Concrete Research Institute, Borås, Sweden \\ +46317722256 \\ $+46317722260$
}

karin.lundgren@chalmers.se

www.chalmers.se

\begin{abstract}
Many studies on the structural effects of corrosion in reinforcement have been conducted. However, most of them are based on artificially corroded test specimens. Thus, the knowledge available entails one major uncertainty, i.e. whether the results are reliable enough to be used for naturally corroded structures. The purpose of this study was to develop a test method and carry out experiments on naturally corroded specimens taken from an existing structure to investigate the anchorage capacity. Beam specimens were taken from the edge beams of a bridge at repair. The specimens showed corrosion-induced damage to a varying extent from no sign of corrosion to extensive cracking and spalling of the concrete cover. A four-point bending test indirectly supported by suspension hangers was chosen. The beams were strengthened with transverse reinforcement around the suspension hangers to avoid premature failure. Eight successful tests were carried out; in all these tests, diagonal shear cracks preceded a splitting induced pull-out failure; i.e. anchorage failure was achieved as intended. The results showed around 10\% lower capacity for the corroded specimens than for the reference ones. The average bond stress in the anchorage zone was estimated based on the applied load and available anchorage length. The stress was about $16 \%$ lower in the beams with corrosion cracks, and $9 \%$ lower in the beams with cover spalling compared to the reference specimens; there was also a larger variation among the damaged specimens than for the reference specimens. The results extend our knowledge concerning the structural behaviour of corroded reinforced concrete structures during field conditions.
\end{abstract}

Keywords: bond, anchorage, natural corrosion, reinforcement, concrete, experiments 


\section{Introduction}

The structural effects of reinforcement corrosion are of major concern in society, as corrosion damage is common in existing infrastructure. The most severe effect of reinforcement corrosion is the volume increase which causes splitting stresses in the concrete, leading to cracking and eventually spalling of the cover. As the reinforcement becomes exposed, the corrosion rate may increase. Cover cracking and spalling affect the bond between the reinforcement and the concrete, i.e. the interaction between the steel reinforcement and the surrounding concrete. This is decisive for both the load-carrying capacity and the ductility in the ultimate state (see Zandi Hanjari et al. (2011) and Coronelli and Gambarova (2004)), as well for the stiffness distribution and deflection in the service state (Val et al. 2009).

The effect of corrosion on bond has been studied by many researchers; for a state-of-the-art report, see fib (2000). Existing analytical and numerical models of the bond of corroded reinforcement have been developed based on experimental investigations of artificially corroded specimens. However, there are reasons to believe that the deterioration caused by natural corrosion does not have the same effect on the structural behaviour as the deterioration caused by artificial corrosion. Experimental evidence found in the literature shows that common methods of accelerated induced corrosion, i.e. admixed chloride, impressed current and wet/drying techniques, may change the morphology of the corrosion products to varying extents. The most influencing factor is probably the corrosion rate achieved by each method. Saifullah and Clark (1994) carried out pull-out tests on specimens subjected to impressed currents of different densities from 40 to $4000 \mu \mathrm{A} / \mathrm{cm}^{2}$, corresponding to a rate of approximately 20 to 200 times faster than naturally induced corrosion. Spurious bond deterioration was found for specimens subjected to impressed currents higher than $250 \mu \mathrm{A} / \mathrm{cm}^{2}$. Another study showed that the electrochemistry in naturally induced corrosion differed from accelerated corrosion (Austin et al. 2004). A dramatic reduction of the corrosion time from years to days is a rather strong justification for using accelerated induced corrosion in laboratory tests. However, great care should be taken in interpreting the results and extrapolating them to field conditions. Tests on naturally corroded concrete members are essential to investigate the reliability and representativeness in field conditions of the existing models, which are based on investigations of artificially corroded concrete members. 
In this study, the anchorage capacity of naturally corroded steel reinforcement was investigated experimentally. The test set-up was carefully chosen and designed by using NonLinear Finite Element Analysis in a Master's thesis project supervised by the authors, see Berg and Johansson (2011). The bond and anchorage behaviour was examined through measurements of applied load, free-end slip and mid-span deflection.

\section{Test Specimens}

In a search of suitably naturally corroded specimens during which several objects were examined, the edge beams from the Stallbacka Bridge located outside Trollhättan, Sweden were chosen. The bridge is $1,392 \mathrm{~m}$ long, crossing the Göta River. The outermost slabs and edge beams were replaced during an extensive rehabilitation between 2010 and 2012. The Stallbacka Bridge was built in 1981 and is thus only 30 years old. The severity of the deterioration was impaired by poor bridge design. The amount of reinforcement across the cast joints in the slab was inadequate; therefore, the edge beams carried more load than they were designed for, leading to large cracks. The cracks opened up for chlorides from de-icing salts; furthermore, the open cracks store up free water that increases the risk of severe frost damage. Transverse cracks in the joints of the slab also accelerated the chloride penetration. It is important to note that structures exposed to aggressive environments are susceptible to different types of deterioration, e.g. corrosion, frost, sulphate attack, etc. In the case of the Stallbacka Bridge, however, corrosion was the main cause of deterioration. The bridge also showed signs of frost deterioration; however, this was not studied in this piece of research.

The edge beams showed varying extents of corrosion-induced damage, from no sign of corrosion to extensive cover-cracking resulting in the spalling of concrete covers. This was considered to be an advantage, since it made specimens with varying damage levels possible. Based on the damage patterns, the test specimens were categorized into three different groups: Reference (R) specimens without any visible cracks; Medium (M) specimens with spalling cracks; and Highly $(\mathrm{H})$ damaged specimens with cover spalling. The geometry of the edge beams was also suitable for bending tests, which makes it possible to evaluate the anchorage behaviour at a structural level. 
In Fig. 1, the geometry of the edge beams is shown. These beams were $350 \times 400 \mathrm{~mm}^{2}$ in cross-section, with a small inclination of the upper surface. The edge beams were reinforced, both longitudinally and transversally, with ribbed bars. The longitudinal reinforcement consisted of four bars $\varnothing 16 \mathrm{Ks} 60$ bundled into pairs in the upper part, two bars Ø16 Ks60 at the bottom, and one bar Ø16 Ks60 at mid-height of the cross-section to the left in Fig. 1. The transverse reinforcement consisted of $\varnothing 10$ s300 Ks40. Ks 60 and Ks 40 are old Swedish notations for steel reinforcement with a characteristic yield strength of 600 and $400 \mathrm{MPa}$, respectively.

The specimens diverged in several aspects from the drawings because of altering precision in the workmanship when the bridge was erected. The concrete cover to the longitudinal reinforcement varied as shown in Table 1 and Fig. 2 (note that as the specimens were tested upside-down, the beam in Fig. 2 is consequently depicted upside-down compared to Fig. 1). Also, the distance between the transverse reinforcements, i.e. the stirrups, varied. As the longitudinal reinforcements were often spliced, the amount of longitudinal reinforcement varied. However, there were always only two main bars at each bottom corner that slipped in the tests.

The longitudinal reinforcement bars closest to the upper inclined surface of the edge beams were more damaged than other longitudinal bars. Therefore, they were considered more interesting for the investigation of bond and anchorage behaviour. The higher extent of corrosion-induced damage was reasonable since the upper bars were more heavily exposed to de-icing salts during their service life time.

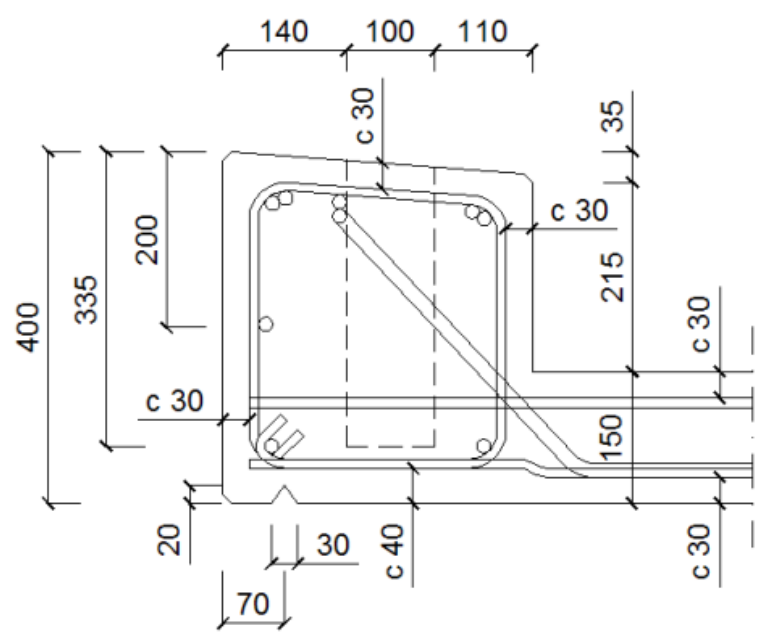

Fig. 1 Cross-sectional detail of the edge beam. Adapted from the bridge drawings; all dimensions are in [mm]. 


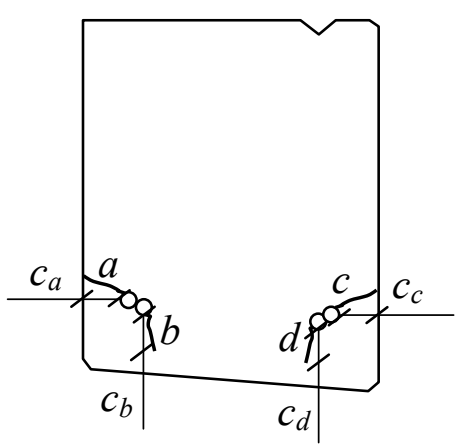

Fig. 2 Notations for concrete cover measurements and spalling cracks.

Table 1. Concrete cover on the side that failed.

\begin{tabular}{|c|c|c|c|c|}
\hline Specimen & $c_{a}[\mathrm{~mm}]$ & $c_{b}[\mathrm{~mm}]$ & $c_{c}[\mathrm{~mm}]$ & $c_{d}[\mathrm{~mm}]$ \\
\hline R1 & 45 & 40 & 55 & 50 \\
\hline R2 & 40 & 60 & 45 & 50 \\
\hline M1 & 45 & 55 & 40 & 40 \\
\hline M2 & 55 & 50 & 40 & 35 \\
\hline M3 & 55 & 40 & 60 & 30 \\
\hline H1 & 45 & 45 & 45 & 40 \\
\hline H2 & 60 & 50 & 40 & 35 \\
\hline H3 & 50 & 35 & 50 & 30 \\
\hline
\end{tabular}

\section{Choice of Test Set-Up}

\subsection{Potential Test Set-Ups}

Potential test set-ups were examined and evaluated. The most promising test configuration was then designed in detail by using the Non-Linear Finite Element Method. The test configuration had to be thoroughly designed to secure anchorage failure for beams with various corrosion damage levels in a common test set-up. Capturing anchorage failure without influencing and disturbing the natural damages of the edge beams was a major objective. In other words, it was of great importance to avoid any damage to the beams during preparation. 
Four different test configurations, as illustrated in Fig. 3, were considered when the test set-up was selected: a pull-out test; a beam-end test; a directly supported four-point bending test; and an indirectly supported four-point bending test.

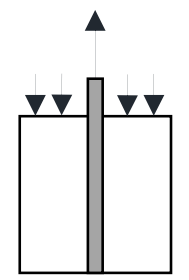

(a)

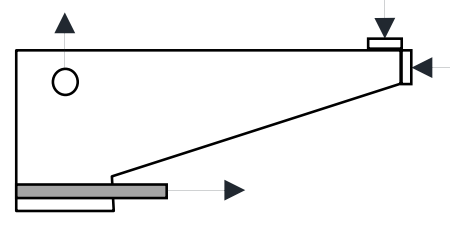

(b)

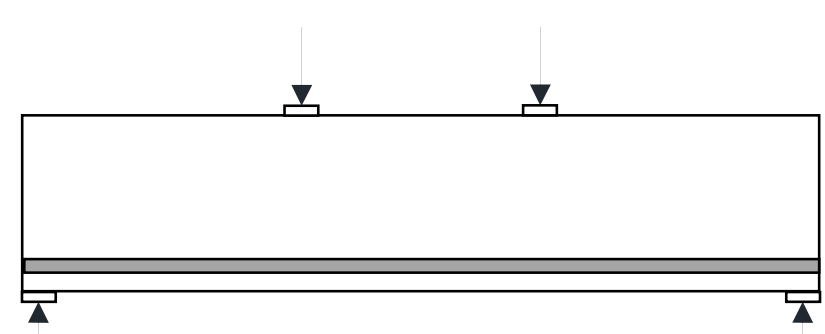

(c)

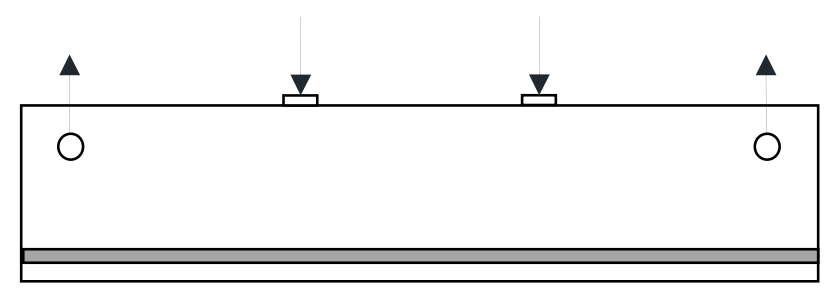

(d)

Fig. 3 Principles of possible test set-ups: a) a pull-out test; b) a beam-end test; c) a directly supported fourpoint bending test; and d) an indirectly supported four point bending test.

The pull-out test was excluded for several reasons. First, it would have been difficult to grip the bundled bars. Second, the eccentric position of the bars would have complicated the test. Finally, the region around the bars would have been disturbed in preparing specimens for pull-out tests, thus influencing the bond properties. Otherwise, as it has a well-defined anchorage length, the pull-out test would have been preferable.

The beam-end test has also a well-defined anchorage length and better represents structural behaviour than the pull-out test. However, also this test set-up involves the difficulty of 
gripping the reinforcement bars and entails a large natural damage impact that should be avoided; accordingly, this test set-up was discarded.

The directly supported four-point bending test has the advantage of excluding any gripping of the bundled bars. Furthermore, because inclined shear cracks often propagate to direct support, it will most likely result in better defined anchorage length in comparison to the indirect support. A concern regarding this test set-up is that the support pressure will to a large extent influence the anchorage behaviour. With external transverse pressure acting in the anchorage region, i.e. along the transmission length, both bond stiffness and strength increase, see e.g. Lundgren and Magnusson (2001) or Zandi Hanjari (2010). As the major influence of corrosion on bond is that the confinement is reduced due to cracking and eventually spalling, it would be inappropriate to use a test set-up which compensates for this weakness as support pressure is not always present in real anchorage situations, e.g. in splices or cut-off regions. Finally, for severely damaged members with cover spalling in the end regions, a test configuration using direct supports would be impossible without repairing the specimens to obtain a flat surface for the supports. As our intention was to study the effect of spalled covers, this would be considered unacceptable. Therefore, the test set-up using a directly supported four-point bending test was left out.

The four-point bending test, indirectly supported by suspension hangers, does not include the problems of gripping the bundled bars, and the part with spalled cover can be left as it is. A disadvantage of the test set-up, however, is that it required strengthening of the available specimens for them to be able to withstand the hanging support reactions. With a carefully designed strengthening, this test set-up was thus considered to be the optimal choice with least disturbance and influence on the natural damage of the edge beams while capturing the structural behaviour.

The edge beams were positioned upside-down when they were tested; thus, the most corroded bars were loaded with tension. The test set-up selected made it possible to evaluate anchorage capacity of beams with cover spalling. Moreover, there was an advantage of avoiding external transverse pressure acting in the anchorage region, i.e. along the transmission length. This was important as the major influence of corrosion on bonded areas is that the confinement is reduced due to cracking and spalling. Since the load was applied on a flat surface instead of an inclined surface, turning the specimens upside-down at testing also facilitated the loading. 


\subsection{Design of Test Set-Up}

The four-point bending test, indirectly supported by suspension hangers, was designed in detail so that an anchorage failure could take place. This was performed in a parametric study prior to actual testing by simulating the test set-up using both two- and three-dimensional Non-Linear Finite Element Analyses. For more details of the analyses, see Berg and Johansson (2011). Several parameters were investigated; the most important parameters were the location of the suspension holes and the position of the concentrated loads. With respect to shear capacity, it was considered to be important to place the load so that the load path crossed at least one stirrup. The parametric study showed that it would be preferable to obtain a rather large shear span; such a span would increase the bending moment, which in turn would increase the tensile stresses in the main reinforcement, thereby making it more likely to obtain anchorage failure. Furthermore, it showed that it would be preferable to place the suspension holes rather close to the end; when they were placed further into the beam, the shear crack appeared further away from the end, resulting in longer anchorage lengths with a more unstable and brittle behaviour.

Local failure around the suspension hole was critical independently of the test settings; therefore, it was concluded that the beams needed to be strengthened through transverse reinforcement. Internal mounting was considered the most promising option. In the method selected, vertical holes were drilled and reinforcing ribbed steel bars were bonded using epoxy adhesive, see Fig. 4. The number of strengthening reinforcing steel bars and their location, dimension and steel quality were designed to avoid the strengthening reinforcing steel to yield. With respect to the load-carrying capacity, it was considered essential to provide the beam with pairs of strengthening bars on both sides of the suspension hole. As the beams were strengthened, the suspension holes could be placed either in the upper or lower parts of the beam. The placement of the holes in the upper half was chosen to avoid the cracking around the suspension hole affecting the anchorage of the main bars. A pilot test showed that without additional measures, anchoring the strengthening bars became critical after the region around the suspension holes had started to crack (Berg and Johansson 2011). To provide additional anchoring of the strengthening bars, they were anchored at the top of the beam with hexagonal nuts and flat steel plates. 


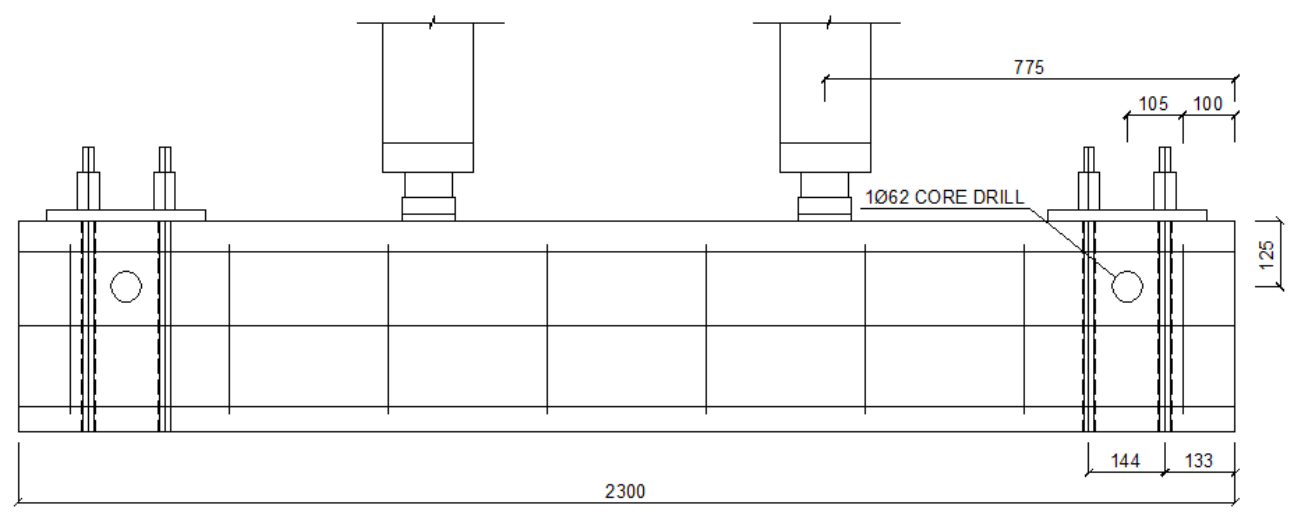

Fig. 4 Test set-up with dimensions in mm (symmetric).

\section{EXPERIMENTS}

All tests were performed at the Structural Engineering Laboratory at the Chalmers University of Technology. The crack patterns of the test specimens were documented before, during, and after the tests. Material tests were carried out on drilled cores, and the main tensile reinforcement bars in three of the specimens were brought out and cleaned after the structural tests had been conducted to enable measurement of the corrosion level.

\subsection{Material Properties}

The cores drilled for the suspension holes were used in compressive tests and in some of the specimens, it was possible to drill cores of larger dimensions for the testing of tensile splitting strength and modulus of elasticity. Drilling of the specimens was performed according to EN 12504-1. The cylindrical compressive strength was tested, according to EN 12390-3:2009, on drilled cores with a height of $110 \mathrm{~mm}$ and a diameter of $55 \mathrm{~mm}$ (see results in Table 2). Splitting tensile tests were carried out according to EN 12390-6:2009 on drilled cores of equal height and diameter of $100 \mathrm{~mm}$ (see results in Table 3). Also, the modulus of elasticity was tested, according to SS 137232 on drilled cores with a height of $150 \mathrm{~mm}$ and a diameter of $75 \mathrm{~mm}$ (see results in Table 4). As seen from these results, the scatter in compressive strength measured is quite large. The average compressive strength of the Medium and Highly damaged specimens was $90-111 \%$ of the strength of the Reference specimen, respectively. The average splitting tensile strength of a Highly damaged specimen was $89 \%$ of that of the Reference specimen. The corresponding relation for the modulus of elasticity was $95 \%$. It may be concluded that the strength of the damaged specimen was probably slightly less than in the Reference specimens, perhaps a reduction of around 5-10\%. 
Table 2. Compressive strength test results of cored specimens taken from the edge beams.

\begin{tabular}{|c|c|c|c|c|}
\hline \multirow[t]{2}{*}{ Category } & \multirow[t]{2}{*}{ Specimen } & $f_{c}$ & $\begin{array}{c}f_{c} \\
\text { average }\end{array}$ & $\begin{array}{l}\text { Standard } \\
\text { deviation }\end{array}$ \\
\hline & & \multicolumn{3}{|c|}{$\mathrm{MPa}$} \\
\hline \multirow{6}{*}{$\begin{array}{c}\text { Reference } \\
\text { (R) }\end{array}$} & R1-1 & 37.8 & \multirow{6}{*}{43.3} & \multirow{6}{*}{10.4} \\
\hline & R1-2 & 39.6 & & \\
\hline & R1-3 & 31.8 & & \\
\hline & R1-4 & 47.8 & & \\
\hline & R1-5 & 41.3 & & \\
\hline & $\mathrm{R} 2$ & 61.7 & & \\
\hline \multirow{7}{*}{$\begin{array}{c}\text { Medium } \\
\text { damaged } \\
\text { (M) }\end{array}$} & M1-1 & 37.8 & \multirow{7}{*}{39.0} & \multirow{7}{*}{6.4} \\
\hline & M1-2 & 33.8 & & \\
\hline & M2-1 & 39.1 & & \\
\hline & M2-2 & 44.8 & & \\
\hline & M2-3 & 30.2 & & \\
\hline & M3-1 & 38.5 & & \\
\hline & M3-2 & 49.2 & & \\
\hline \multirow{4}{*}{$\begin{array}{c}\text { Highly } \\
\text { damaged } \\
(\mathrm{H})\end{array}$} & $\mathrm{H} 2$ & 40.3 & \multirow{4}{*}{48.2} & \multirow{4}{*}{9.9} \\
\hline & H3-1 & 54.6 & & \\
\hline & H3-2 & 39.3 & & \\
\hline & H3-3 & 58.7 & & \\
\hline
\end{tabular}

Table 3. Tensile strength test results of cored specimens taken from the edge beams.

\begin{tabular}{|c|c|c|c|}
\hline \multirow[t]{2}{*}{ Category } & $f_{t}$ & $\begin{array}{c}f_{t} \\
\text { average }\end{array}$ & $\begin{array}{l}\text { Standard } \\
\text { deviation }\end{array}$ \\
\hline & \multicolumn{3}{|c|}{$\mathrm{MPa}$} \\
\hline \multirow{5}{*}{$\begin{array}{l}\text { Reference } \\
\quad \text { (R1) }\end{array}$} & 3.36 & \multirow{5}{*}{3.62} & \multirow{5}{*}{0.32} \\
\hline & 3.46 & & \\
\hline & 3.81 & & \\
\hline & 3.37 & & \\
\hline & 4.09 & & \\
\hline \multirow{3}{*}{$\begin{array}{l}\text { Highly } \\
\text { damaged } \\
\text { (H1) }\end{array}$} & 3.04 & \multirow{3}{*}{3.23} & \multirow{3}{*}{0.28} \\
\hline & 3.09 & & \\
\hline & 3.55 & & \\
\hline
\end{tabular}

Table 4. Modulus of elasticity test results of cored specimens taken from two of the edge beams.

\begin{tabular}{|c|c|c|c|}
\hline \multirow[t]{2}{*}{ Category } & $E_{0}$ & $\begin{array}{c}E_{0} \\
\text { average }\end{array}$ & $\begin{array}{l}\text { Standard } \\
\text { deviation }\end{array}$ \\
\hline & \multicolumn{3}{|c|}{$\mathrm{GPa}$} \\
\hline \multirow{5}{*}{$\begin{array}{l}\text { Reference } \\
\quad \text { (R1) }\end{array}$} & 24.4 & \multirow{5}{*}{24.0} & \multirow{5}{*}{4.08} \\
\hline & 26.7 & & \\
\hline & 17.3 & & \\
\hline & 23.9 & & \\
\hline & 27.7 & & \\
\hline \multirow{5}{*}{$\begin{array}{l}\text { Highly } \\
\text { damaged } \\
(\mathrm{H} 1)\end{array}$} & 21.7 & \multirow{5}{*}{22.8} & \multirow{5}{*}{1.64} \\
\hline & 23.8 & & \\
\hline & 20.7 & & \\
\hline & 22.7 & & \\
\hline & 24.8 & & \\
\hline
\end{tabular}




\subsection{Experimental Set-Up}

As previously described, the test configuration was thoroughly designed to secure anchorage failure for beams with various corrosion damage levels in one common test set-up. A fourpoint bending test indirectly supported by suspension hangers was chosen (see Fig. 4), with a span of $1,890 \mathrm{~mm}$ and a shear span of $570 \mathrm{~mm}$. Since it was considered important to have the suspension holes positioned between two stirrups, these holes were carefully located in advance.

The edge beams were strengthened through transverse reinforcement around the suspension holes to avoid premature failure of the beam at the support suspension holes. Steel bars of $\varnothing 20$ were used for the strengthening in drilled cores injected with epoxy. These strengthening bars were anchored at the top of the beam with hexagonal nuts and flat steel plates (Fig. 4). The mechanical locking of the bars by means of threaded coupling provided adequate anchorage to avoid failure at the suspension holes.

The load was applied by two symmetrically placed hydraulic jacks connected to the same hydraulic pump to bring out loads of the same magnitude. Each load was measured by load cells placed on top of each jack. Steel plates and wood fibre plates were placed between the hydraulic jacks and the beam; the plates measured $100 \mathrm{~mm}$ along the beam and $250 \mathrm{~mm}$ across the beam. The tests were conducted by a displacement control mechanism in the midspan. The loading rate was $0.1 \mathrm{~mm} / \mathrm{min}$ up to the maximum failure load; loading was also stopped at several levels to observe and document cracks. After the anchorage failure, the loading rate was increased to $0.5 \mathrm{~mm} / \mathrm{min}$. Displacement transducers measured the vertical displacements relative to the floor in mid-span, in sections of the suspensions, in addition to the loads. Furthermore, one displacement transducer per main bar was placed on the beam ends to measure the free-end slip of the longitudinal reinforcement. The end slip was measured relative to a point on the beam end located about $80 \mathrm{~mm}$ above the uppermost main reinforcement bar. All measurements were continuously stored in a data-log, with an amplitude of $1 \mathrm{~Hz}$. The crack development was also continuously registered. 


\section{$5 \quad$ Results}

\subsection{Crack Documentation before Testing}

Before the tests, existing cracks and spalling of the cover were documented. Photos of the corrosion damaged specimens before testing are shown in Fig. 5. The crack widths of the splitting cracks on the side of the beam that failed are shown in Table 5; the notations of the cracks are similar to the covers (see Fig. 2). Since one side of the beam had cover spalling, specimen H3 was considered to be Highly damaged. However, in the test, the specimen failed on the other side, where there were only splitting cracks.

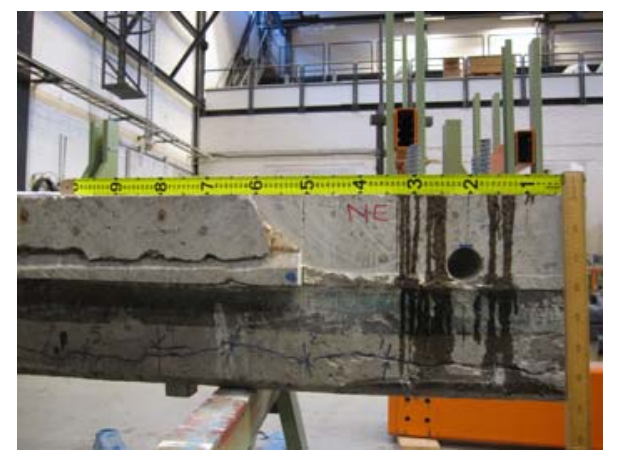

Medium damaged M1

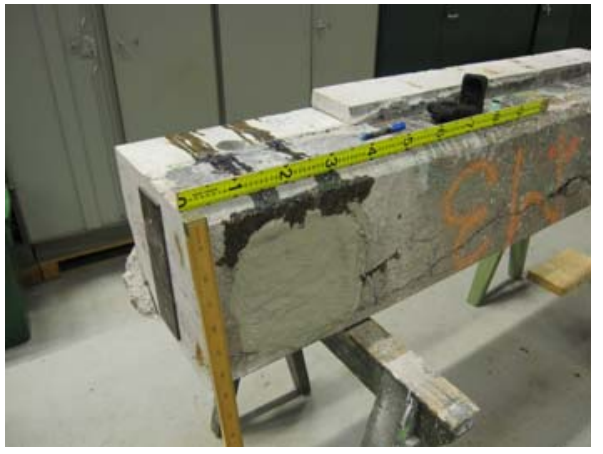

Medium damaged M3

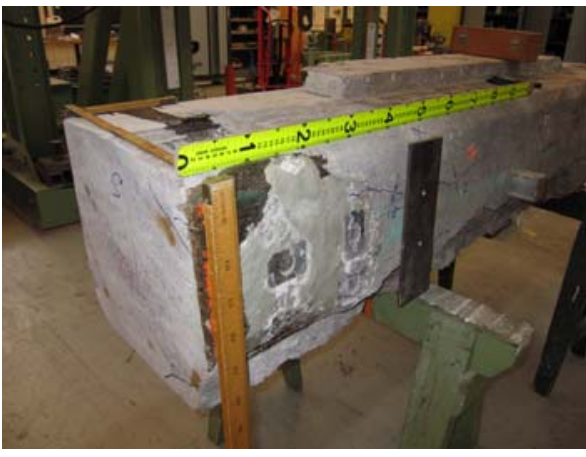

Highly damaged $\mathrm{H} 2$

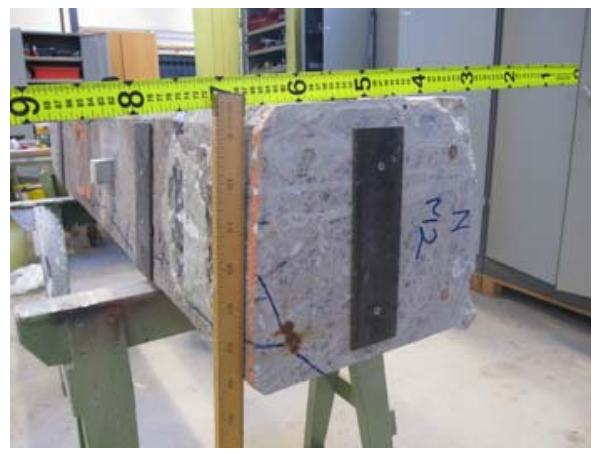

Medium damaged M2

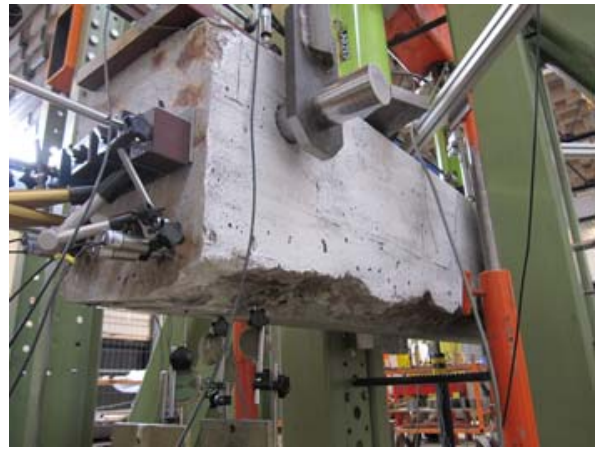

Highly damaged $\mathrm{H} 1$

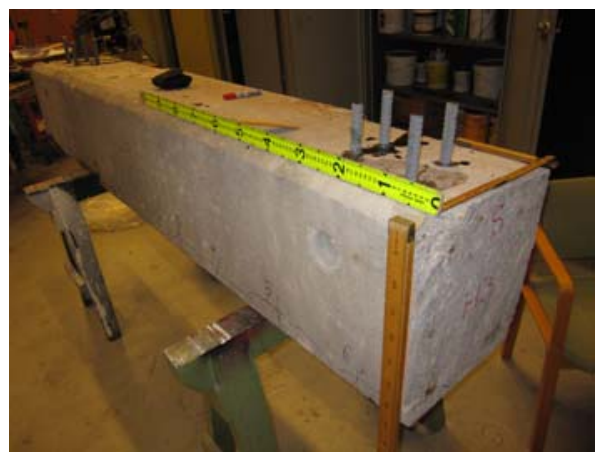

Highly damaged H3

Fig. 5 Photos of corroded damaged specimens before testing, the side that later failed. Note that specimen H3 was considered to be Highly damaged even though there were only splitting cracks on the side that failed, as the other side had cover spalling. 
Table 5. Observed crack width in the anchorage zone before testing, on the side that failed in tests.

\begin{tabular}{|c|c|c|c|c|}
\hline Specimen & $\begin{array}{c}a \\
\text { Crack width } \\
{[\mathrm{mm}]}\end{array}$ & $\begin{array}{c}b \\
\text { Crack width } \\
{[\mathrm{mm}]}\end{array}$ & $\begin{array}{c}c \\
\text { Crack width } \\
{[\mathrm{mm}]}\end{array}$ & $\begin{array}{c}d \\
\text { Crack width } \\
{[\mathrm{mm}]}\end{array}$ \\
\hline R1 & - & - & - & - \\
\hline R2 & - & - & - & - \\
\hline M1 & 0.2 & 0.1 & - & 0.1 \\
\hline M2 & - & - & - & 2 \\
\hline M3 & - & - & spalled & spalled \\
\hline H1 & - & - & spalled & spalled \\
\hline H2 & - & 0.1 & 0.08 & 0.75 \\
\hline H3 & - & - & & \\
\hline
\end{tabular}

\subsection{General Test Behaviour}

Eight test specimens were successfully tested. All beams evidenced similar behaviour in terms of crack development and failure mode. An example of a load versus mid-span deformation graph, together with cracks appearing, is shown in Fig. 6. In this particular test, the crack pattern was measured by digital image correlation. The first flexural cracks occurred at around $80-110 \mathrm{kN}$ near the centre of the beam. With increased loading, flexural-shear cracks began to appear in the shear span. The inclined shear cracks occurred at around $160-180 \mathrm{kN}$ (see Table 6). Thereafter, the load continued to increase; the anchorage was then effectively loaded and the bond capacity came to play an important role. In some tests (as in the test shown in Fig. 6), second shear cracks closer to the support began appearing at around $220-240 \mathrm{kN}$. 

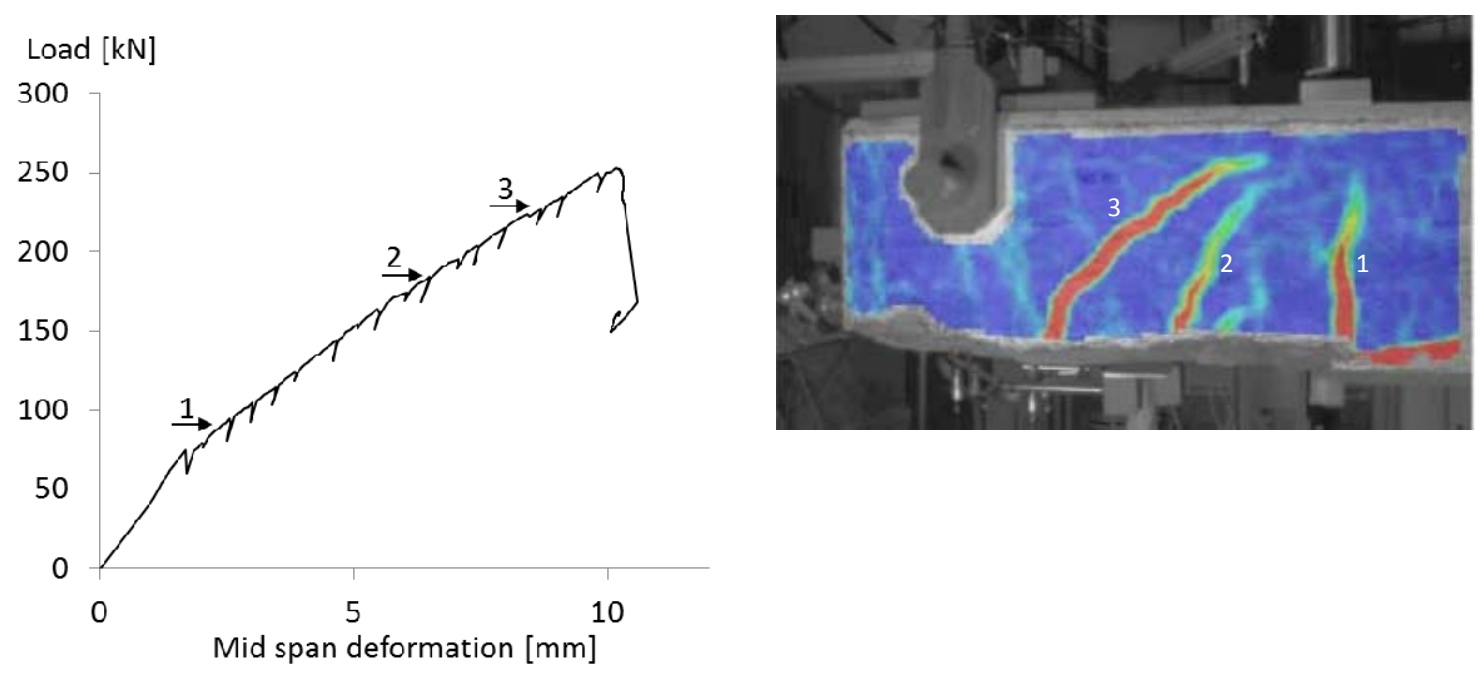

Fig. 6 Test H3. a) Average load in each of the hydraulic jacks versus measured deformation at mid span (not corrected for support settlements), b) Crack pattern measured with digital image correlation during the test. 1-3 marks when the cracks appeared.

The free end of the tensile bars began to slip at a load level of about 190-200 kN and the final anchorage failure took place, on the average, at a load level of $275 \mathrm{kN}$ for the Reference beams (R) and $240 \mathrm{kN}$ for the damaged beams at both levels ( $\mathrm{M}$ and $\mathrm{H}$ ) (see Table 7). As can be seen from the values of the failure loads in Table 7, the scatter was larger for the Highly damaged beams. Photos of some beams after they had been tested are shown in Fig. 7; as seen, splitting cracks occurred around the main bars at failure.

Table 6. Load levels in each hydraulic jack (in $\mathrm{kN}$ ) corresponding with the initial inclined shear cracks observed during the tests.

\begin{tabular}{|c|c|c|c|}
\hline Beam No. & 1 & 2 & 3 \\
\hline Reference (R) & $160-170$ & $175-185$ & - \\
\hline Medium damaged (M) & $185-195$ & $225-235$ & $215-225$ \\
\hline Highly damaged (H) & $170-180$ & $165-180$ & $155-175$ \\
\hline
\end{tabular}

Table 7. Maximum failure loads in each hydraulic jack (in $\mathrm{kN}$ ) obtained in the experiments.

\begin{tabular}{|c|c|c|c|c|c|}
\hline Beam No. & 1 & 2 & 3 & Average & $\begin{array}{c}\text { Standard } \\
\text { deviation }\end{array}$ \\
\hline Reference (R) & 270.1 & 281.2 & - & 275.6 & 7.9 \\
\hline Medium damaged (M) & 234.9 & 243.8 & 250.2 & 243.0 & 7.7 \\
\hline Highly damaged (H) & 255.4 & 225.1 & 244.4 & 241.6 & 15.4 \\
\hline
\end{tabular}




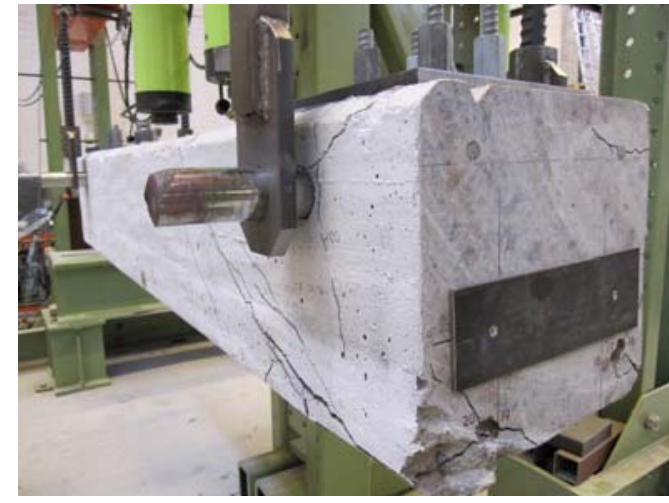

Reference specimen R1

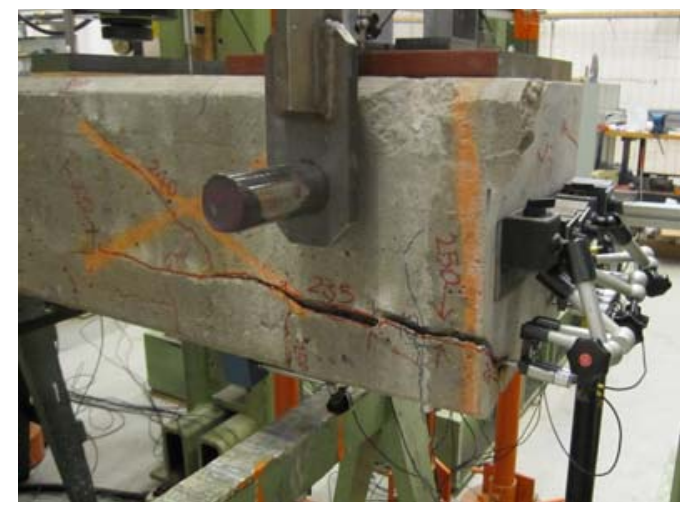

Medium damaged M3

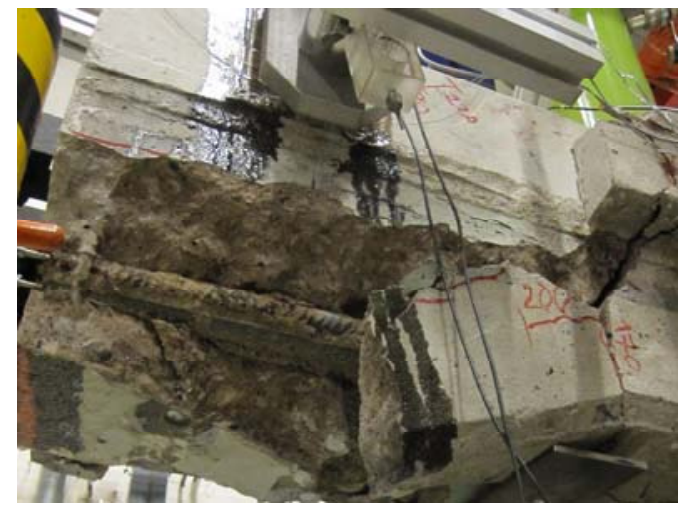

Highly damaged $\mathrm{H} 2$

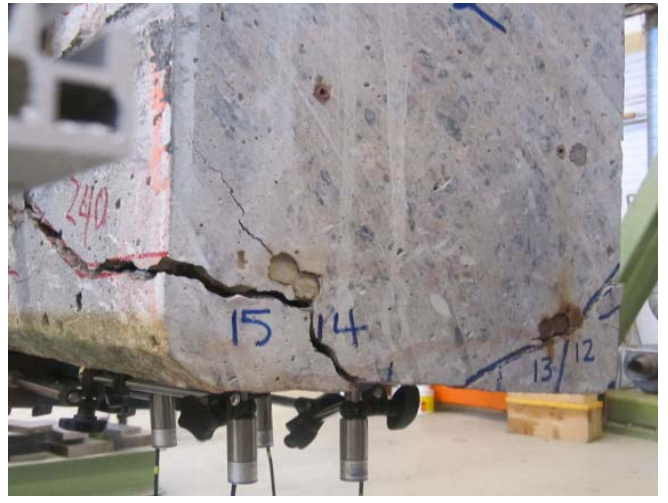

Medium damaged M2

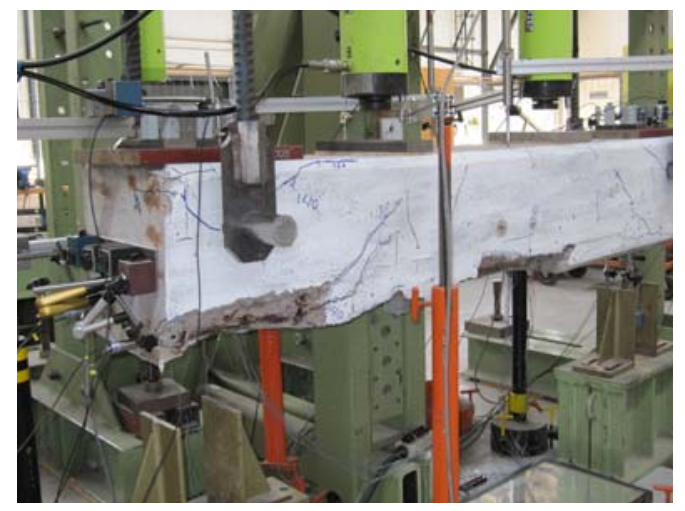

Highly damaged H1

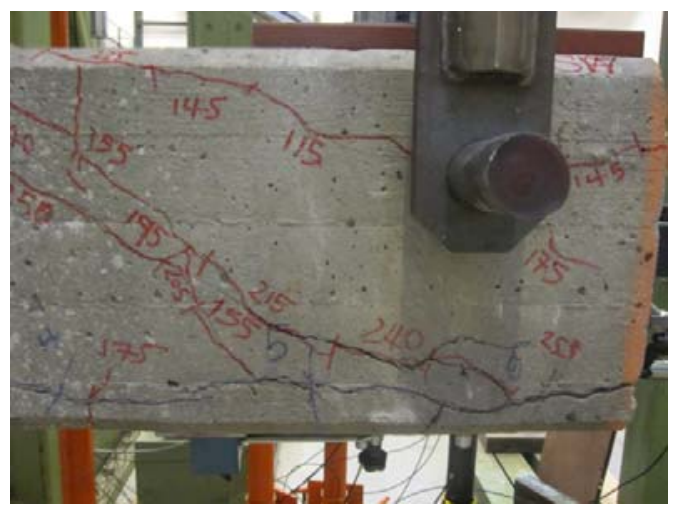

Highly damaged H3

Fig. 7 Failure and crack pattern on some of the beams after testing.

\subsection{Available Anchorage Length}

After the tests had been completed, the available anchorage length was evaluated based on the crack pattern. It was measured from the point where the main bars and the inclined shear crack intersect to the end cross section (see examples in Fig. 8). Only the section of the beam that failed was evaluated; however, the available anchorage length was evaluated on both the 
back and front sides. The average of the back and front sides is given in Table 8. As seen, the available anchorage lengths show only small variations; thus, the position of the shear crack was more greatly impacted by the load arrangement than by the corrosion level.

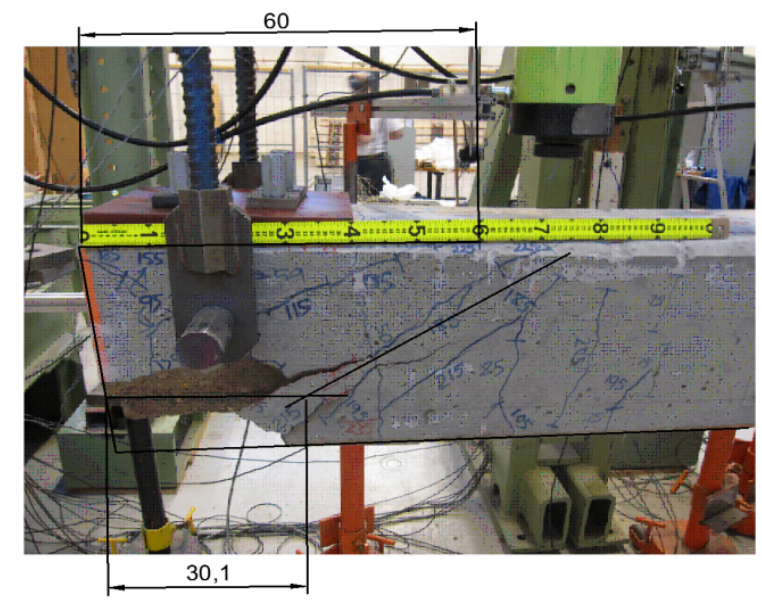

(a) Reference beam R2

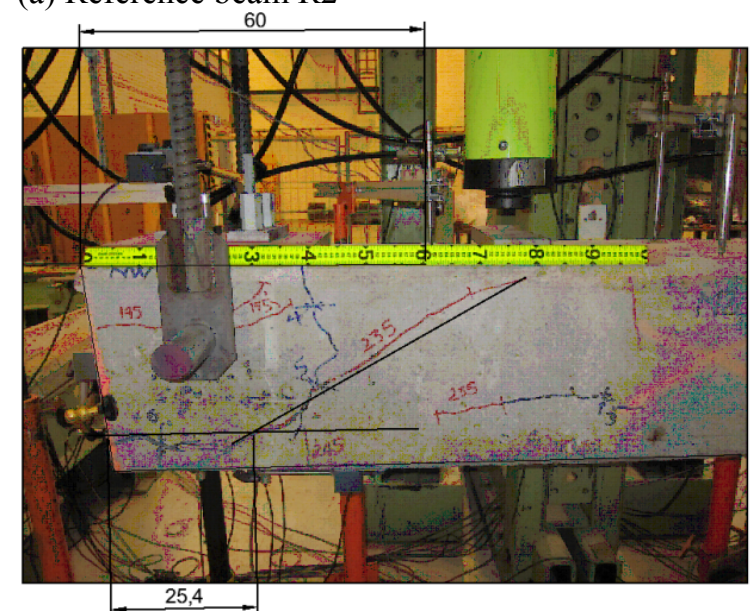

(b) Medium damaged M2

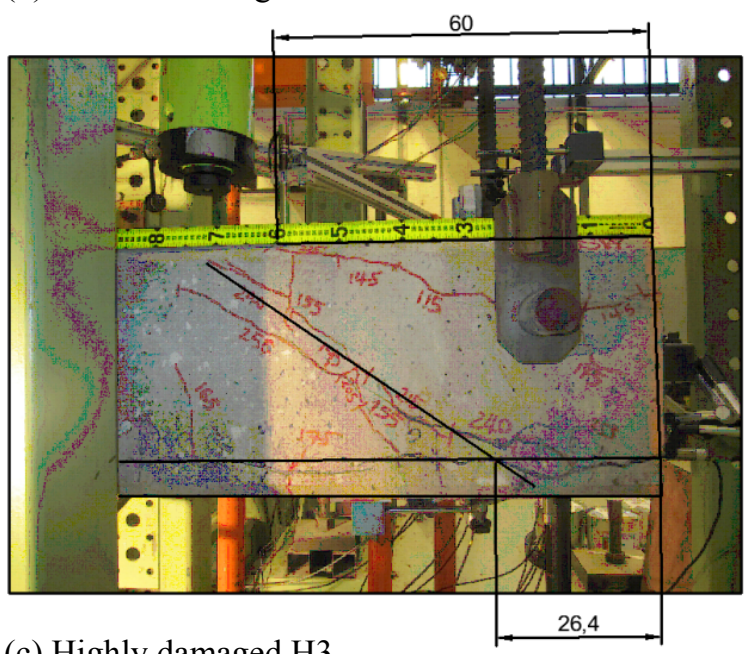

(c) Highly damaged H3

Fig. 8 Available anchorage length in some of the beams; measured from the end cross section to the point where the main bars and the inclined shear crack intersect. 
Table 8. Available anchorage lengths $\left(l_{a}\right)$ in the experiments (in $\mathrm{cm}$ ); the given values for each specimen are the average of the measured anchorage length on both edges of the failure zone.

\begin{tabular}{|c|c|c|c|c|}
\hline Beam No. & 1 & 2 & 3 & Average \\
\hline Reference (R) & 29.4 & 30.5 & - & 30.0 \\
\hline Medium damaged (M) & 31.4 & 27.2 & 34.1 & 30.9 \\
\hline Highly damaged $(\mathrm{H})$ & 32.2 & 29.7 & 27.3 & 29.7 \\
\hline
\end{tabular}

\subsection{Average Bond Stress versus Free End Slip}

The tensile force in the longitudinal reinforcement, $F_{t}$, was estimated by assuming that no forces were transferred over the inclined shear cracks (see Fig. 9). The inner lever arm was estimated to be $0.9 d$, where the effective height, $d$, was taken as the average of the main bars. From equilibrium, the tensile force in the longitudinal reinforcement was thus calculated as follows:

$F_{t}=\frac{P \cdot l_{s}}{0.9 d}$

where $P$ represents the point load and $l_{s}$ the shear span, which in all tests equalled $570 \mathrm{~mm}$. The average bond stress along the bundled bars was then calculated based on the tensile force, available anchorage length and the circumference of the bundled bars. In CEN (2005), an "equivalent bar" is used, meaning that two bars in a bundle would be replaced by one bar with the same cross-sectional area; this would correspond to a circumference of the bundled bars of $\phi \pi \sqrt{2}$, i.e. around $4.44 \phi$. However, Jirsa et al. (1995) used an upper and a lower limit of $\phi 2 \pi$ and $\phi(\pi+2)$, respectively (see Fig. 10), for the circumference of two bundled bars, corresponding to $6.28 \phi$ and $5.14 \phi$. Here, the average value of this upper and lower limit was chosen. Since there were two bundles of two bars each, the average bond stress was calculated as follows:

$$
\hat{\tau}=\frac{F_{t}}{l_{a} \cdot(3 \pi+2) \cdot \phi}
$$

where $l_{a}$ is the available anchorage length, evaluated as described in Section 5.2. The maximum average bond stress for all tests is given in Table 9. As seen, the Reference specimen showed the highest bond stress with only minor scatter. The Medium damaged specimen had on the average around $16 \%$ lower maximum bond stress, while the Highly 
damaged specimen only showed a 9\% reduction compared to the Reference specimen. The variation in results for the damaged specimens was considerably larger than for the two Reference specimens.

As mentioned in Section 4.2, the free-end slip of the longitudinal reinforcement bars was measured at the end faces. It was noted from the measurements that the free-end slips of two bundled bars were in all tests quite similar; i.e. the two bundled bars always slipped together. Furthermore, the difference between the two bundles in the cross-section was also minor. An example of the variation of the slip in the different bars can be seen in Fig. 11. Typically, one of the two bundles started to slip slightly before the other bundle. However, the difference between the different bars in one test was minor; therefore, average results will mainly be discussed below.

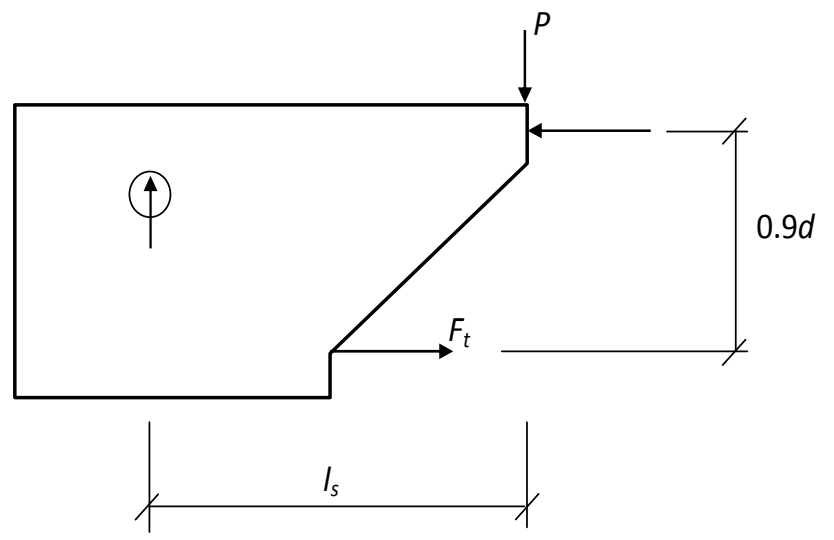

Fig. 9 Assumptions for estimation of the tensile force in the longitudinal reinforcement.

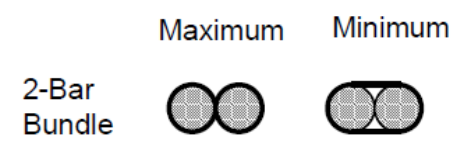

Fig. 10 Maximum and minimum values of the circumference of two bundled bars, from Jirsa et al. (1995).

Table 9. Average bond stress in the experiments (in MPa).

\begin{tabular}{|c|c|c|c|c|c|}
\hline Beam No. & 1 & 2 & 3 & Average & $\begin{array}{c}\text { Standard } \\
\text { deviation }\end{array}$ \\
\hline Reference (R) & 9.79 & 9.83 & - & 9.81 & 0.02 \\
\hline Medium damaged (M) & 7.85 & 9.37 & 7.44 & 8.22 & 1.02 \\
\hline Highly damaged (H) & 8.49 & 7.95 & 9.77 & 8.74 & 0.93 \\
\hline
\end{tabular}




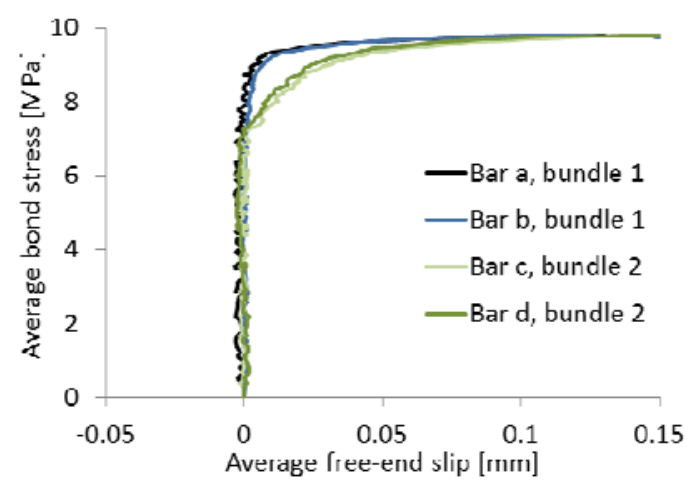

Fig. 11 Average bond stress versus the measured free-end slip, for all bars at the side that failed in test R1. Note that only the first part with small slip values is shown.

In Fig. 12, the average bond stress, calculated from Equations 1 and 2, is plotted against the measured average free-end slip for all tests. As seen, the measured slip is often negative in the beginning but in later tests, it was verified not to be a really negative slip (Gestsdóttir and Guðmundsson 2012) but was rather caused by a deformation of the end cross-section between the reinforcement bars and the plate where the LVDTs measuring the slip were attached (see Fig. 13). The test results by Gestsdóttir and Guðmundsson (2012) showed that this finding only had any substantial effect on the first part and explained the negative slip values. The results of the measurements in this study are, therefore, still of interest and show a trend when the end slip starts increasing and the levels thereof. As seen in Fig. 12, the average end slip started to increase at a load slightly below the maximum load in all tests. A stable slip increase could be registered until the maximum load was reached, and initially with decreasing load. At a slip varying between 0.15 to $0.7 \mathrm{~mm}$ in the different tests and a load slightly smaller than the maximum load, the tests were unstable; thus, the slip suddenly increased with decreasing load, causing brittle failures. A residual bond capacity of around $70 \%$ of the maximum bond capacity could be seen for large slip values in most tests.

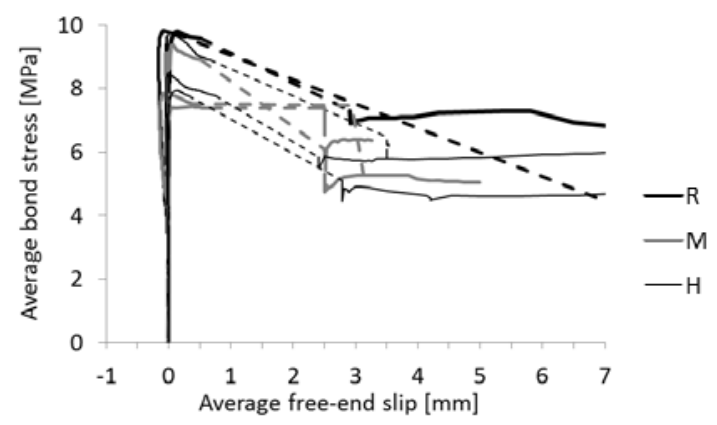

(a)

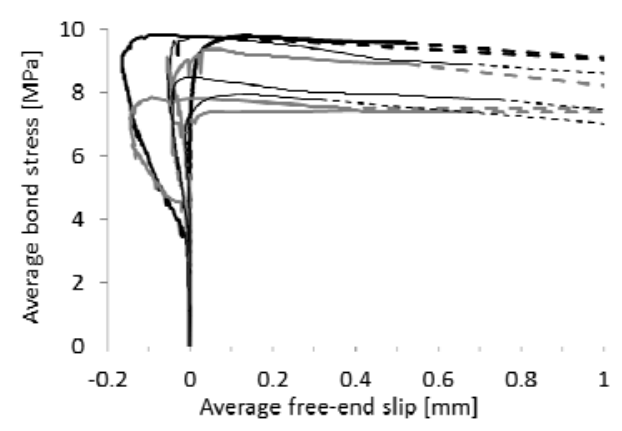

(b)

Fig. 12 Average bond stress versus the average measured free-end slip, for all tests. Dashed parts indicate that there is a jump in the measurements. (b) is an enlargement of (a) 


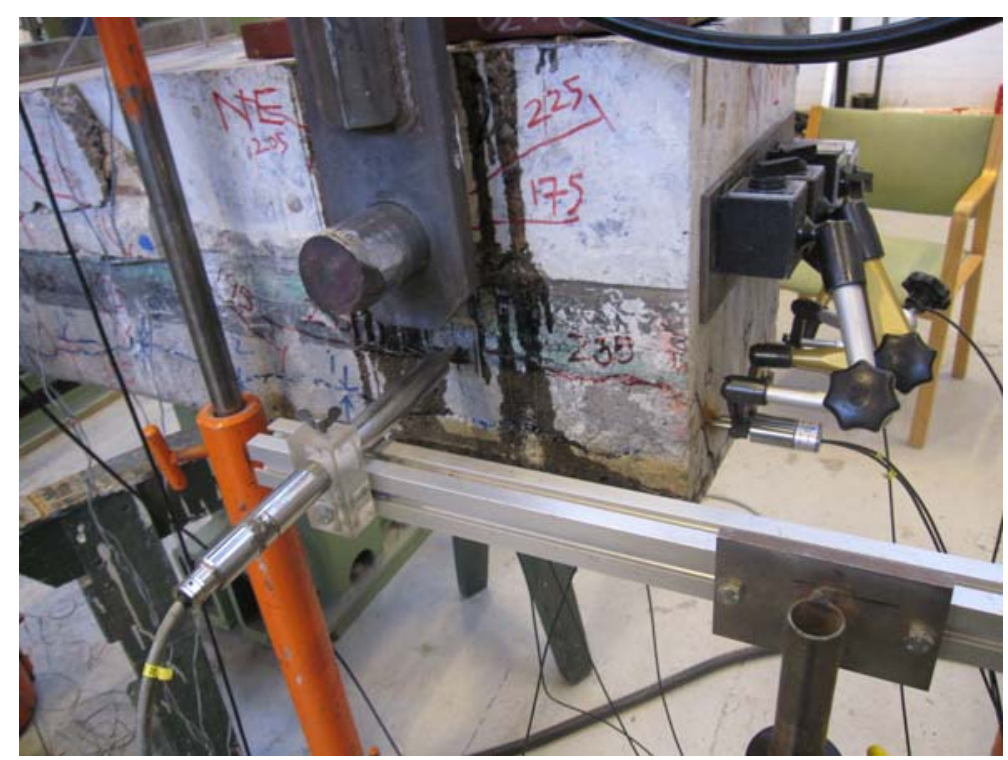

Fig. 13 Attachment of LVDTs measuring the free-end slip of the longitudinal bars.

\subsection{Corrosion Measurements}

Three of the specimens were broken after the bending tests, and the main reinforcement was taken out and cleaned. The three specimens were chosen to be a Reference specimen (R2), a Medium specimen (M1), and a Highly damaged specimen (H3). The reinforcement bars in the R2 specimen didn't show any signs of corrosion, while the reinforcement bars from the M1 and H3 specimens showed severe pitting corrosion damage (see Fig. 14). Typically, the pitting corrosion took place on one half of a reinforcement bar, in some cases almost completely eliminating the ribs; while the other half of the reinforcement bar was almost undamaged. The side of the bar that was damaged shifted, sometimes by only a decimetre but on other occasions by an interval of half a metre. The parts of the bars at the ends where anchorage failure took place were cut to $580.1 \mathrm{~mm}$ long pieces, using a lathe to enable a high degree of precision. 


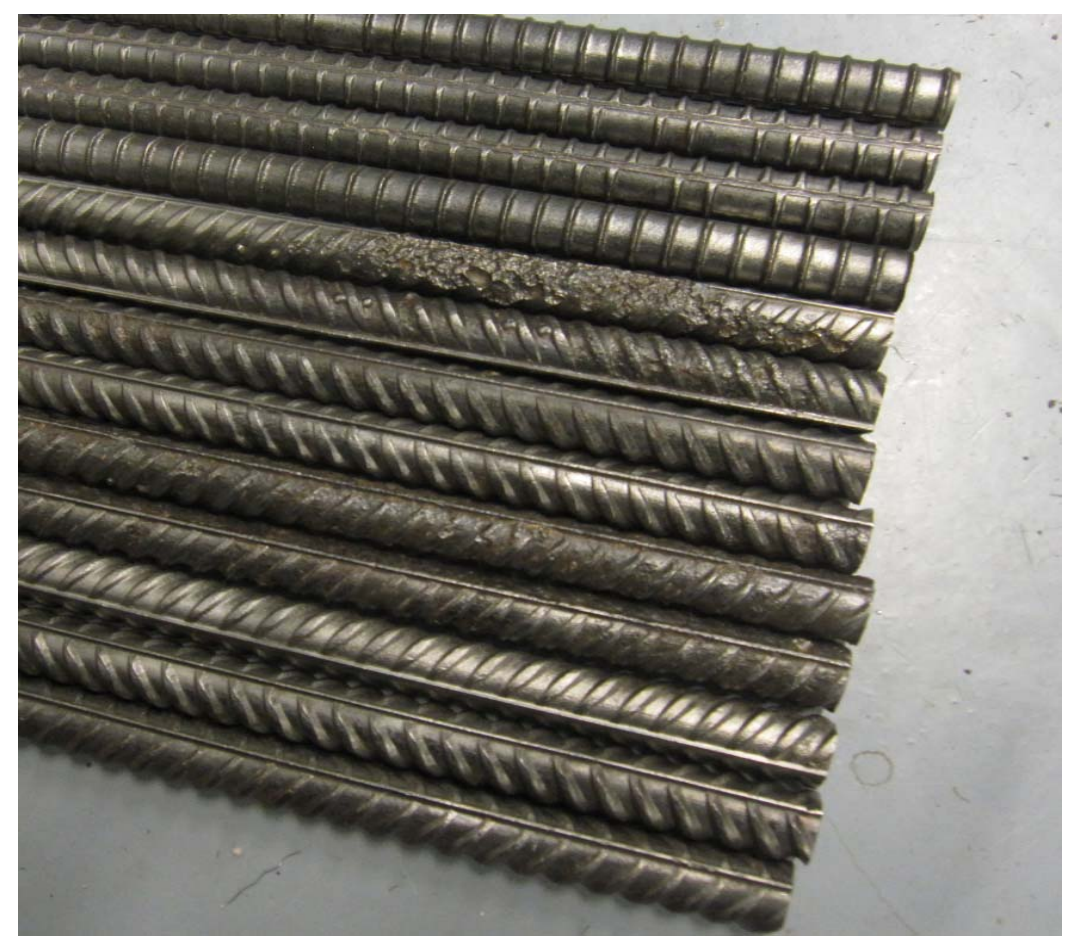

Fig. 14 Reinforcement bars, from top to bottom from specimens R2, H3, and M1.

The bars were cleaned and weighed according to ASTM G1-03, with their actual weights recorded in Table 10. The intention was to use these values to estimate the corrosion weight loss. Of course, a major problem was that reference weights of the bars when they were uncorroded were missing; naturally the bars were not weighed before they were placed in the bridge. The intention was to use the weights of the rebars for the Reference specimen; however, unluckily, those were of a different type than the others; R2 had bars with straight ribs while M1 and H3 had bars with inclined ribs (see Fig 14). Therefore, the bars from the Reference specimen R2 could not be used as reference weight to calculate the weight loss. As the reinforcement was only brought out of three of the specimens, the reinforcement type in the other specimens is unknown. In one of the other specimens, H3, it was possible to find a $580.1 \mathrm{~mm}$ long piece that was uncorroded (positioned outside the anchorage region). This part was also cleaned and weighed. When using this as reference, the weight loss in the damaged specimens was estimated at 2-3\%. It can be noted that the nominal weight of a rebar of type Ks $60 \phi 16 \mathrm{~mm}$ is $1.67 \mathrm{~kg} / \mathrm{m} \pm 5 \%$ according to the standard valid when the bridge was built (SIS 2125 15, Second Edition). The weight loss calculated using the nominal weight as a reference was $1-2 \%$. 
Table 10. Measured weight of $580.1 \mathrm{~mm}$ long parts of the reinforcement.

\begin{tabular}{|c|c|}
\hline Specimen & $\begin{array}{c}\text { Weight } \\
{[\mathrm{g}]}\end{array}$ \\
\hline & 949.6 \\
& 949.6 \\
& 950.2 \\
& 950.2 \\
\hline & 967.6 \\
Medium damaged (M1) & 963.9 \\
& 941.4 \\
& 928.3 \\
\hline & 940.7 \\
Highly damaged (H3) & 947.4 \\
& 963.9 \\
& 973.3 \\
\hline Uncorroded part from H3 & 980.0 \\
\hline
\end{tabular}

After cleaning and weighing, the bars were tested in tension. The length of the free parts of the bars in the tests was $440 \mathrm{~mm}$; results are shown in Fig. 15. As seen, the bars from the Reference specimen R2 actually had approximately the same yield strength as the bars from the Highly damaged specimen H3. The uncorroded part of the bar from specimen H3 is probably a better reference; compared to that, the yield strength of the corroded bars was reduced by $0.5-20 \%$ and the ultimate strength by $4-26 \%$, on the average 10 and $13 \%$, respectively. It is the pitting corrosion that causes the reduction in capacity to be larger than the weight loss. The pitting corrosion is also the cause of the large reduction in ductility which can be seen in Fig. 14; the ultimate strain was roughly halved for the bars from the Medium damaged specimen and only one third remaining for those from the Highly damaged specimen compared to those from the Reference specimen. In the results of other researchers, the ductility of the reinforcement is also decreased by corrosion, see e.g. Du et al. (2005), Almusallam (2001), and Cairns et al. (2005). 


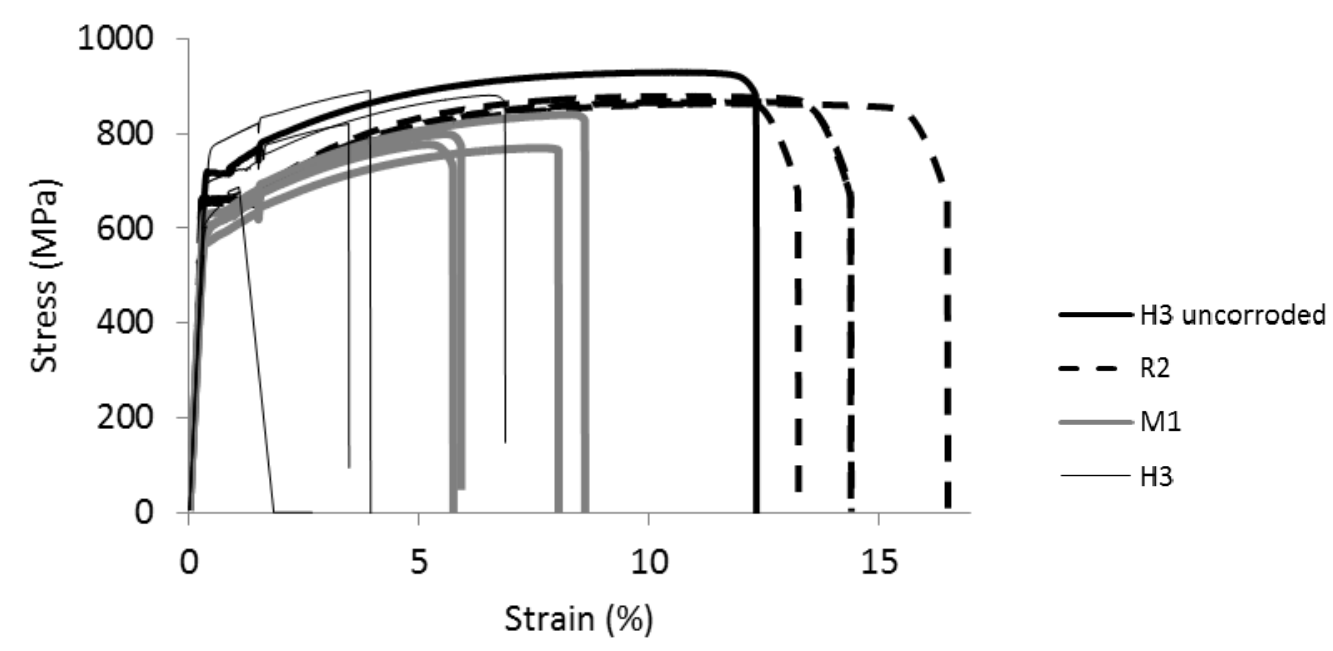

Fig. 15 Stress versus strain in tensile tests of reinforcement bars.

\section{Conclusion and Outlook}

Eight edge beams with varying levels of natural corrosion damage were tested in indirectly supported four-point bending tests. In all tests, diagonal shear cracks preceded a splitting induced pull-out failure; i.e. an anchorage failure was achieved as intended. The results show around $10 \%$ higher load-carrying capacity for the Reference specimens than for the damaged specimens. The available anchorage length after the tests was measured as the distance between the point where the main bars and the inclined shear crack intersect to the end cross section. This did not vary a great deal; thus, the position of the inclined shear crack was mainly affected by the load arrangement. The average bond stress in the anchorage zone was estimated from the applied load and available anchorage length. It was about $16 \%$ lower than in the Reference specimens in the beams with corrosion cracks and $9 \%$ lower in the beams with cover spalling. The average bond stress also showed a larger variation for the damaged specimens than for the Reference specimens. It should be mentioned that the strength of the damaged specimens was probably slightly less than in the Reference specimens; material tests were scattered but indicated a 5-10\% reduction.

Since extensive scatter can be expected in this type of work with test specimens taken from an existing bridge, additional tests will be carried out. In a second series, specimens from the Northern section of the Stallbacka Bridge will be tested. The tests will produce benchmark data of anchorage of naturally corroded reinforcement. To evaluate the results in a more 
sophisticated way than in this study, detailed Non-Linear Finite Element Modelling will be performed using the bond and corrosion model developed in Lundgren (2005) and further developed in Zandi Hanjari et al. (2011).

\section{References}

ASTM Standard G1-03. Standard Practise for Preparing, Cleaning and Evaluating Corrosion Test Specimens, ASTM International, 2003

Almusallam AA (2001) Effect of degree of corrosion on the properties of reinforcing steel bars. Constr Build Mater 15 (8):361-368

Austin SA, Lyons R, Ing MJ (2004) Electrochemical behavior of steel-reinforced concrete during accelerated corrosion testing. Corrosion 60 (2):203-212

Berg F, Johansson D (2011) Design of test set-up using FEM: Pilot tests on anchorage of naturally corroded reinforcement. Master of Science Thesis, Chalmers University of Technology, Gothenburg

Cairns J, Plizzari GA, Du Y, Law DW, Franzoni C (2005) Mechanical properties of corrosion-damaged reinforcement. ACI Mater J 102 (4):256-264

CEN (2005) EN 1992-1-1:2005. Eurocode 2: Design of concrete structures - Part 1-1: General rules and rules for buildings. European Committee for Standardization

Coronelli D, Gambarova P (2004) Structural assessment of corroded reinforced concrete beams: Modeling guidelines. Journal of Structural Engineering 130 (8):1214

Du YG, Clark LA, Chan AHC (2005) Effect of corrosion on ductility of reinforcing bars. Mag Concr Res 57 (7):407-419

fib (2000) Bond of reinforcement in concrete, State-of-art report. Fédération internationale du béton, prepared by Task Group Bond Models, Lausanne

Gestsdóttir E, Guðmundsson T (2012) Bond Behaviour of Naturally Corroded Reinforcement in Concrete Structures: Experimental and numerical study. Master of Science, Chalmers University of Technology, Gothenburg

Jirsa JO, Chen W, Grant DB, Elizondo R (1995) Development of bundled reinforcing steel. Center for transportation research, Univeristy of Texas at Austin, Texas, USA

Lundgren K (2005) Bond between ribbed bars and concrete. Part 2: The effect of corrosion. Mag Concr Res 57 (7):383-395

Lundgren K, Magnusson J (2001) Three-dimensional modelling of anchorage zones in reinforced concrete. ASCE Journal of Engineering Mechanics 127 (7):693-699

Magnusson J (2000) Bond and Anchorage of Ribbed Bars in High-Strength Concrete. Ph.D. Thesis, Chalmers University of Technology, Göteborg

Saifullah M, Clark LA Effect of corrosion rate on the bond strength of corroded reinforcement. In: Swamy RN (ed) Proceedings of International Conference: Corrosion and corrosion protection of steel in concrete, University of Sheffield, 24 28 July 1994. Sheffield Academic Press, pp 591-602

Val DV, Chemin L, Stewart MG (2009) Experimental and Numerical Investigation of Corrosion-Induced Cover Cracking in Reinforced Concrete Structures. ASCE Journal of Structural Engineering 135 (4):376-385

Zandi Hanjari K (2010) Structural Behaviour of Deteriorated Concrete Structures. Doctoral Thesis, Chalmers University of Technology, Gothenburg

Zandi Hanjari K, Lundgren K, Plos M, Coronelli D (2011) Three-dimensional modelling of structural effects of corroding steel reinforcement in concrete Structure and Infrastructure Engineering 9 (7):702-718. doi:10.1080/15732479.2011.607830 